\title{
IDENTIDAD FEMENINA Y HUMANIZACIÓN DEL MUNDO. APROXIMACIÓN A LA DETERMINACIÓN DE LA ESPECIFICIDAD FEMENINA COMO PARÁMETRO ANTROPOLÓGICO-NORMATIVO
}

Rodrigo Guerra López

\section{RESUMEN}

El presente estudio pretende realizar una investigación fenomenológica sobre la especificad de lo femenino y el problema de la fundamentación antropológica de la diferenciación sexual. La feminidad es analizada en diversos planos que gradualmente manifiestan que ésta es una perfección óntica y un valor que habita en toda la persona de la mujer y que tiene su raíz más profunda en el alma y no en la pura corporeidad. A la luz de esto, finalmente se muestra la importancia que posee la reivindicación de la especificidad de la mujer en la reconstrucción de un mundo más humano.

\section{ABSTRACT}

The present study tries to perform a phenomenological investigation on the specificity of feminity and on the problem of the anthropological foundation of sexual differentiation. Feminity is analyzed in diverse dimensions that gradually show that it is an ontic perfection and a value that exists in the whole person of the woman and which has its deepest root in the soul and not in pure corporeity. Finally, it is argued the importance of vindication of the specificity of women in the reconstruction of a more buman world. 
Palabras clave: mujer; femenidad; diferenciación sexual; antropología femenina; normativa antropológica.

\section{INTRODUCCIÓN}

Hace casi ocho años inicié mis reflexiones sobre el fundamento antropológico de la diferenciación sexual. En aquel entonces, las preguntas que abordé estaban fuertemente jaloneadas por los temas y problemas que emergieron en torno al "Año Internacional de la Mujer" y en particular alrededor de las nociones de "perspectiva de género" y de "equidad de género" ${ }^{1}$. El desafío era tratar de descubrir si existían razones fundadas para sostener que la masculinidad y la feminidad eran perfecciones puramente corpóreas, explicables desde un punto de vista cultural o si había una justificación más profunda de tipo metafísico.

El análisis permitió observar que existían datos fenoménicos en los diversos niveles de configuración de la persona y de la personalidad que demandaban una explicación radical y transfenoménica sobre la diferenciación sexual. La diversidad biológica, instintiva, cultural, y psíquica entre varones y mujeres ofreció datos que permitieron redescubrir, desde este tema, la existencia de un principio vital que actúa como "forma corporis", como forma sustancial del cuerpo y proponer, así, que la persona masculina y la persona femenina

Esta investigación fue publicada como: Guerra López, Rodrigo, «Pensar la diferencia. Reflexiones sobre la condición femenina y el fundamento antropológico de la diferenciación sexual", en Medicina y Ética. Revista Internacional de Bióetica, Deontología y Ética Médica., Facoltá di Medicina e Chirurgia dell'Universitá del Sacro Cuore-Universidad Anáhuac., Vol. VII., No. 4., octubre-diciembre., 1996. Este texto volvió a aparecer en el libro: A.A. V.V., Temas actuales de Bioética., México., Editorial Porrúa., 1999., pp.109-123. 
gozan de diferenciación sexual principalmente por el alma que determina al cuerpo y no solamente por el cuerpo (de manera más bien accidental) como tradicionalmente se ha sostenido ${ }^{2}$.

En esta ocasión trataré de ahondar en la especificidad femenina, es decir, intentando descubrir los elementos que, más allá de roles sociales convencionales, pueden ayudarnos a apreciar lo femenino en cuanto femenino para, de esta manera, colocar las bases antropológico-normativas que permitan replantar algunas vías para la humanización de las personas y de las sociedades.

Tengo que reconocer, desde el inicio de esta exposición, que no es común el que un varón hable sobre la esencia de la feminidad y sobre el papel que ésta juega en el proceso de humanizar el mundo. Esto responde a dos razones que vale tener en cuenta. La primera es más o menos evidente: la experiencia de lo específico femenino es accesible primariamente a quien la vive desde dentro y sólo indirectamente lo es para el varón que la constata exteriormente a través de la relación interpersonal, por medio de la Literatura y en general a través de símbolos, gestos y datos que ofrecen indicadores, muchas veces confusos, de este fenómeno.

La segunda razón a veces no es tan evidente, pero es preciso también reconocerla: los varones experimentamos una cierta dificultad para apreciar y aprehender totalidades como 
la propia del fenómeno de la feminidad. No sólo es que no vivamos esta experiencia desde dentro, sino que realmente nos cuesta trabajo comprender a la mujer en cuanto mujer debido a la peculiar configuración de algunos aspectos de nuestro psiquismo interno, que si bien son educables, no es común el que, de hecho, realmente se les eduque con esta dirección. Sé que esta afirmación es temeraria, pero trataré de justificarla un poco en las líneas siguientes.

La exposición incluirá diversos incisos que, sin embargo, poseen cuatro momentos principales: a) El papel metodológico de la experiencia sobre lo humano; b) el fundamento de la diferenciación sexual y la especificidad de lo femenino; c) el significado de la feminidad en el contexto de la controversia y crisis sobre lo humano y; d) la hipótesis sobre algunas vías para la reconstrucción de lo humano.

\section{LA IMPORTANCIA DEL MÉTODO}

Somos de la opinión que muchos problemas en torno a la delimitación de lo femenino podrían ahorrarse si fuesen enunciadas con claridad las condiciones metodológicas que el fenómeno de la mujer exige de suyo. Esto quiere decir que no es indiferente el uso de un método o de otro, al momento de ingresar en esta temática. El método debe ser adecuado al objeto de investigación. La realidad es la que norma el acceso metodológico, no viceversa.

Antes de enunciar cualquier pregunta sobre la naturaleza femenina es preciso advertir que la feminidad acontece como dato en la experiencia. La experiencia de lo femenino se ofrece, pues, como un cierto mostrarse que, si bien no es fácil precisar, sí puede ser percibido como una realidad objetiva 
que se ofrece con una evidencia que le es propia. Esta experiencia tiene que ser leída por parte de la inteligencia en su significado (inducción esencial) para así poderla explicar e interpretar de manera adecuada (reducción). La explicación y la interpretación deben buscar detenerse en lo irreductible, es decir, deben saber detenerse en el límite que el fenómeno por sí mismo coloca y que reclama no ser desfigurado al momento de tratar de entenderlo ${ }^{3}$.

\section{LA DIFERENCIACIÓN SEXUAL NO ES INDIFEREN- TE EN LA CONSTITUCIÓN DE LA EXPERIENCIA DE LO HUMANO}

¿Qué significa todo esto? En primer lugar lo que quiere decir es que, más allá de las teorías particulares sobre el conocimiento, si nos disponemos a volver a las cosas mismas, la experiencia se nos da como un primum: como un lugar en el que se inician los conocimientos sensibles e intelectuales que, eventualmente, permitirán remontar por mucho la mostración del aparecer como aparecer. En este sentido, la experiencia que tenemos sobre el mundo si bien es compleja y amplia, yace, descansa, en una experiencia originaria, indubitable y riquísima cualitativamente, que es la experiencia de lo humano y que denota que, antes de vivirla y experimentarla, el ser humano es. Dicho en palabras más breves: cuando conozco algo me doy cuenta (concomitantemente) que soy. Este "darme cuenta" no se agota en la percepción sensible, sino que es un darme cuenta que abraza tanto el sentir como el entender mi propia realidad, aunque sea de modo confuso. 
La experiencia de lo humano es la experiencia sobre el ser propio que es la base sobre la que se despliega toda comprensión de la realidad. Esta experiencia, luego de su darse originario, se enriquece con la vida moral y con el trato con otros seres humanos que, si bien se mantienen ajenos a mí, me permiten descubrirme y eventualmente entender que todos participamos de una experiencia humana común.

Precisamente en este proceso de enriquecimiento paulatino de la imagen que vamos construyendo sobre lo humano, emerge con singularidad la experiencia de lo femenino. Lo humano no acontece de un modo asexuado o puramente masculino, sino pletórico de elementos propiamente femeninos que integran una imagen complexiva en la que sería absurdo sostener que la sexualidad resulta indiferente.

A pesar de la densa cultura patriarcal que enfatiza el papel del varón en la vida social, hasta momentos en los que prácticamente queda subordinado y hasta suprimido el papel de la mujer ${ }^{4}$, la presencia femenina marca cualitativamente el modo como lo humano se devela para una persona. No sólo los momentos excelsos de plena realización y proyección social de la mujer colaboran a este proceso. También los momentos arduos en que lo femenino es desdibujado, ocultado, lastimado o acallado colaboran a descubrir la irreductibilidad de la mujer en cuanto mujer que no puede negar su identidad aun en circunstancias difíciles o contradictorias. 


\section{LA UNIDUALIDAD DE LO HUMANO}

Agustín de Hipona, Tomás de Aquino y más recientemente Karol Wojtyla, han ofrecido valiosas apreciaciones sobre la indubitable presencia del sí mismo ante sí mismo, que afianza la base para la experiencia humana fundamental 5 . Sin embargo, hoy con una mayor conciencia sobre el valor de la diferenciación sexual, es posible advertir que esta experiencia sobre lo humano posee una unidualidad sin la cual la apreciación de lo humano quedaría como mutilada. La percepción respecto de mi propio ser no madura si no concursan elementos masculinos y femeninos en la constitución de mi rostro auténtico.

En efecto, la experiencia nos muestra que lo humano aparece bajo dos modalidades diversas, sin dejar de ser bumana ninguna de ellas. Por una parte, varones y mujeres participamos de una identidad cualitativa innegable. Ambos poseemos cuerpo viviente, tenemos inteligencia, voluntad, afectos. Ambos somos capaces de interpretar y de crear cosas superando -al menos relativamente- los condicionamientos físicos, instintivos y pulsionales.

Sin embargo, la diferencia también emerge concomitantemente. Antes de detallarla es preciso constatar algo: la experiencia de lo humano es una experiencia que madura al descubrir una alteridad que se contradistingue de mi yo. La diferenciación sexual expresa un límite constitutivo de nuestra naturaleza. Por más que exista una identidad cualitativa, la 
diversidad corpórea, cultural y psíquica entre varón y mujer me ofrece no simplemente a un "otro-yo" sino a un "otro" que, si bien es un "Otro-yo", su "yo" no está configurado exactamente del mismo modo que el mío. Por eso, descubrir que el "tú femenino" es alteridad respecto de mi "yo masculino" es cualitativamente más intenso y diverso que una suerte de descubrimiento neutro de la relación "yo-tú" (que no hace referencia explícita a la diferenciación sexual).

De este modo, la diferenciación sexual es un locus: es un lugar en el que la verdad sobre el propio límite aparece con particular fuerza. El "Otro" en tanto que posee elementos con identidad cualitativa respecto de mi "yo", ofrece una continuidad experiencial en el plano de lo común. El "Otro" - en tanto que "diverso sexualmente»- se convierte, para mí, en un ser fascinante y enigmático por mostrar una discontinuidad experiencial novedosa. La persona femenina es "como yo", pero es diversa en un cierto plano que se encuentra al interior de su "yo". Así las cosas, el enigma del otro es máximo cuando se trata de un otro diferente sexualmente de mí. Esto que podría parecer de repente una explicación puramente académica, adquiere una gran vivacidad existencial cuando descubrimos, en nuestra propia experiencia, que lo fascinante del sexo opuesto radica en esa simultaneidad de identidad y diferencia que hace que se suscite una singular curiosidad por descubrir cómo es el otro -la otra- en su misterio.

\section{ALTERIDAD CON RECIPROCIDAD RELACIONAL}

Esta observación nos permite encontrar un nuevo elemento: la alteridad causada por la diferenciación sexual es una alteridad que invita a la reciprocidad relacional. Si bien la persona es un sujeto social, y la sociabilidad se ejerce indistintamente 
con personas del mismo o de diverso sexo, podemos advertir que la relación establecida entre el varón y la mujer es un caso modélico del carácter social, o mejor aún, "comunional" del ser humano.

Sin agotar todas las dimensiones personales en las que se plasma lo masculino y lo femenino, baste mirar que, hasta en el orden puramente corpóreo, la sexualidad manifiesta de manera plástica que un ser humano no se realiza como humano cuando permanece encerrado en sí mismo, "enclaustrado". El ser humano es apertura hacia el "otro-diverso-sexualmente". Toda la conformación corpórea -hasta en el nivel de la configuración genética- dice "alteridad-heterosexual". La alteridad es una tensión constitutiva de la persona que se expresa a través del cuerpo de una manera sumamente intensa en todo nivel. El cuerpo humano es ya apertura, pero lo es especialmente cuando esta apertura, este "ser-para-otro", se transforma en donación heterosexual. Así, la diferenciación sexual posibilita un tipo de unidad más fuerte y estrecha que la que se puede dar entre personas del mismo sexo, es decir, el "servarón" y el "ser-mujer" posibilita que dos personas se entreguen totalmente (corpórea y afectivamente) y eventualmente realicen, de una manera incomparablemente elevada, el «seruno-para-el-otro".

Este tema podría explorarse en múltiples dimensiones. Baste señalar, en esta ocasión, que la conciencia del propio límite que emerge al constatar la diferenciación sexual, persuade al varón no sólo que necesita de la mujer y que la mujer necesita del varón, sino que cada uno posee en sí mismo una plenitud que el otro no tiene y que es deseable compartir. En otras palabras, la diferenciación sexual abre a la persona a 
una modalidad del don de sí que es inviable entre personas del mismo sexo. Ésta es una de las razones más profundas por las que la cuestión de la diferencia sexual no es reconducible sin más a un asunto de roles sociales convencionalmente definidos, sino que exige un esclarecimiento propiamente ontológico en el que la complementariedad varón-mujer aparezca como una dinámica que emerge desde la plenitud entitativa del ser personal sexuado ${ }^{6}$.

\section{LA PREGUNTA CORRECTA: ¿QUIÉN ES EL VARÓN? ¿QUIÉN ES LA MUJER?}

Con estos datos -sucintamente anotados- es posible, entonces, lanzar una pregunta a la experiencia que se nos ofrece: ¿quién es el varón y quién es la mujer que conforman la integralidad de la experiencia de lo humano que yo vivo en mi interior?

En efecto, la pregunta no puede ser ¿qué es el varón y qué es la mujer? Una pregunta que sobre este fenómeno subrayara el "qué" y no el "quién", asumiría de entrada que no es clara en la experiencia inicial la diferencia entre cosas y personas: entre "ser-algo" y "ser-alguien". Sin embargo, esto es contrafáctico. En otro lugar, hemos explicado de manera amplia que desde el momento más originario en el que nuestra conciencia despierta, la diferencia entre "ser-algo" y "ser-alguien", emerge como una dato per se notae quoad omnibus, es decir, evidente para todos. Esto significa que, al momento en que la inteligencia humana se da cuenta que algo es, no puede no

Cfr. Scola, Angelo., Identidad y diferencia. La relación hombre-mujer., Madrid., Encuentro., 1989., p.54. 
darse cuenta tangencialmente que el sujeto que la realiza es un alguien-que-es ${ }^{7}$.

De esta manera, el modo metodológicamente más adecuado para preguntar por la feminidad y la masculinidad es precisamente el que no elude que la fuente de esta experiencia es un sujeto personal, es un "alguien" que posee un sello diferencial de tipo sexual en todos los órdenes de su persona (corpóreo, afectivo, psíquico, etcétera).

Ahora bien, vale la pena advertir que si el presente estudio tiene como objeto aproximarnos principalmente a la dimensión femenina de lo humano, con lo ya afirmado se logra entrever que esto no puede realizarse sin mencionar con cierta frecuencia lo masculino, ya que la unidualidad relacional de la experiencia humana lo demanda.

\section{VERIFICAR LA FEMINIDAD COMO ATRIBUTO TOTAL DE LA PERSONA (FEMENINA)}

La feminidad es una perfección que no existe per se sino que atraviesa todo el ser personal de la mujer. De hecho, al hablar de persona no se puede prescindir señalar su diferenciación sexual ya que ésta no es una dimensión accidental de ella misma sino que es una característica que brota del tipo de perfección intrínseca que la hace tener un cierto modo de ser. Utilizando el lenguaje de Aristóteles podemos decir que el acto -la "entelequia"-, la forma que le da configuración, orden y unidad al cuerpo es el responsable de la configuración, orden y unidad también desde el punto de vista sexual. 
Este aserto puede ser verificado a grandes rasgos del siguiente modo: por una parte, la pura capacidad de combinación química de los ácidos nucleicos, aminoácidos (proteínas y enzimas) y demás elementos constituyentes de un ser humano vivo no es suficiente para que la "información" genética que explica su constitución (genética, tisular, orgánica, sistémica, etcétera) se estructure y configure al modo como sucede de hecho. Los elementos que conforman el cuerpo humano no dan razón totalmente de su unidad entitativa y funcional. Nadie puede negar que el cerebro y el sistema ganglionar colaboran a mantener la unidad del cuerpo. Sin embargo, la funcionalidad de estos órganos es condición necesaria pero no suficiente para explicar la unidad completa del viviente en cuanto viviente.

Dicho de otro modo: si se analizan con cuidado los componentes químicos que integran, por ejemplo, el DNA podemos percatarnos que son prácticamente idénticos en todos los seres vivos. ¿Por qué en unos se articulan de un modo y por qué en otros de otro? Al formular esta pregunta debemos entender que no es lo mismo que el profesional de la Genética nos describa cómo está conformado el genoma humano a la explicación sobre el por qué está ordenado de este modo preciso y no de otro. Las causas quia, los cómos, y las causas propter quid, los porqués, si bien están íntimamente relacionadas, no son lo mismo. Este tipo de fenómenos parecen demandar el reconocimiento de un principio vital que explique el orden y unidad corpóreos y que no sean uno más de estos factores corpóreos. Esto es lo que precisamente pareciera relanzar la clásica noción de entelequia, ya que éste término designa un tipo de actualidad que pre-contiene el telos que ha de ser realizado operativamente y que, desde el 
inicio más primario del ser vivo, da razón de la naturaleza, la unidad entitativa y la ruta funcional que éste desplegará gradualmente.

Esto nos permite, entonces, entender que la feminidad $y$ la masculinidad en el orden corpóreo remiten a una feminidad y a una masculinidad más profunda que proviene del elemento determinante de la configuración corpórea, es decir, de la entelequia, de la forma sustancial, del principio vital.

La segunda manera de constatar que la diferenciación sexual y particularmente la feminidad provienen del principio vital y, por lo tanto, que es un sello diferencial no sólo corpóreo sino también psíquico es el análisis del desarrollo cognitivo y afectivo de la mujer.

En efecto, de entre los múltiples datos que develan la singularidad psíquica de la mujer es importante señalar, al menos, que existen algunas peculiaridades que el proceso del conocimiento reviste cuando acontece en la mujer. Parece ser que podemos encontrar que las mujeres suelen tener una particular habilidad para la comprensión intelecto-sensitiva concreta, es decir, para captar receptivamente de modo cuasiinmediato los contenidos inteligibles en las situaciones concretas de la vida cotidiana. Este fenómeno suele ser denominado "intuición". Por intuición no queremos señalar una suerte de dinamismo irracional que de manera más o menos arbitraria apuntara hacia ciertos contenidos. Lo que queremos expresar es que, en la mujer, la actividad intelectiva se encuentra mucho más fusionada con la sensitiva que en el varón, permitiendo esto una aprehensión de lo real, en tanto que real, más holística e inmediata. Así, la "intuición femenina" no versa 
sólo sobre qué son las cosas (esencia), sino también trata sobre su contenido cualitativo sensible (cualidades sensibles) y sobre la importancia que de suyo tienen (valor). La intuición femenina, por ello, es inteligible, sensitiva y valoral: no deja de lado la esencia que permite la universalización, ni ignora el valor y los aspectos concretos que posibilitan el justipreciar la bondad intrínseca de las cosas y de las personas.

En contraste, los varones tendemos más al pensamiento abstracto y a la discursividad. Esto quiere decir que, en lo masculino, encontramos subrayadas las funciones analíticas o de disociación de las partes que constituyen un todo y los procesos de conexión lógico-deductiva que permiten, entre otras cosas, la realización de la argumentación silogística. Asimismo, en la percepción de la realidad, los varones solemos atender a su faceta apetecible, a aquello que nos parece "Conveniente": a la perfección de la cosa en cuanto ella desarrolla alguna capacidad humana ${ }^{8}$. Por ello, en el varón, el aprecio de las cosas parece originarse bajo la huella de una cierta propensión al dominio y la instrumentalización. No nos parece exagerado sostener, entonces, que una posible explicación a la crisis de la modernidad ilustrada ha sido el unilateral énfasis que lo masculino ha impuesto en la cultura y en las instituciones a través de la impostación del canon racionalinstrumental que, para articularse de una manera humana, habría de ser corregido precisamente con el aporte de la racionalidad específicamente femenina.

\& Usamos la palabra "valor" en el sentido que le ha asignado Dietrich von Hildebrand. Por otro lado, la noción de "bien" es usada aquí en el significado aristotélico del término. En nuestra opinión, la distinción entre bien y valor es capital para éste y otros temas ético-antropológicos. Cfr. Cardona, Carlos., Metafísica del bien y del mal., Pamplona., Eunsa., 1987; Von Hildebrand, Dietrich., Ética., Madrid., Encuentro., 1983. 
El descubrir que el varón desarrolla más la ratio instrumental, analítica y discursiva, y la mujer más el intellectus contemplativo, valoral y sintético, nos permite sostener que la mujer en el contexto del orden de la creación, parece tener una actividad de suyo más elevada que el varón ya que, en el orden de las funciones de la inteligencia, la ratio es una operación subordinada al intellectus, es decir, la capacidad discursiva se ordena a la comprensión del totum et integrum.

Otro aspecto que configura la estructura psíquica de la mujer como mujer es de orden afectivo. Es cierto que todo ser humano es un integrum de elementos corpóreos, psíquicos y espirituales. Sin embargo, en ella hallamos una mayor integración, es decir, un modo de ser donde al entendimiento, la voluntad y los sentimientos se les dificulta actuar separados. Más aún: pareciera que estos tres dinamismos estuvieran como enlazados por un cierto centro afectivo que, en ocasiones, algunos llaman "corazón". Este "enlace» no produce que cada capacidad humana pierda su especificidad, sin embargo, le confiere a cada una de ellas una cierta unidad psicológica y emotiva especial. Esto parece explicar precisamente que la mujer, aun al realizar las actividades más modestas, comprometa todos los dinamismos de su persona y descubra como algo muy trabajoso el escindir alguna función de otra (por ejemplo, fracturar la actividad intelectual de la vida afectiva) ? Nada más lejano de lo femenino que la vida escindida o partida. En la mujer todo lo que acontece goza de una singular unidad. 
Gracias a esta mayor integración de los dinamismos en la mujer, ella tiene una especial sensibilidad a los temas y problemas más específicamente humanos. No es raro ver cómo la mujer, de modo natural, suele inclinarse por actividades y preocupaciones donde la dignidad de la persona humana, el amor, la libertad y los derechos fundamentales se encuentran olvidados u oscurecidos. En esta misma línea argumentativa, también es importante reconocer que en la mujer la búsqueda y encuentro de un significado unitario de la existencia parece surgir de un modo más espontáneo y concreto que en el varón, el cual aun cuando también vive de modo dramático la búsqueda de sentido, suele tender a categorizarlo de modo abstracto.

Si esto es así, entonces podemos afirmar que la articulación del principio vital que organiza el cuerpo y que explica las operaciones superiores de tipo intelectivo, volitivo y afectivo se encuentra, en la mujer, de manera más dilatada, integrada y fusionada que en el varón. Utilizando nuevamente el lenguaje de los griegos, podemos decir que la unidad hilemórfica en la mujer posibilita una mayor integración que en el varón.

Esto no significa que en el varón no exista propiamente unidad hilemórfica, ni que el varón posea otra esencia diversa a la femenina o que exista una diferencia esencial en términos de facultades. Lo que significa es que el alma femenina parece activar al cuerpo femenino como cuerpo vivo de una manera más íntima, haciendo de la persona un ente en cierto sentido más "simple»... Si esto no es así, no entendemos entonces por qué existe una diferenciación en los procesos cognitivos y en el papel unificador que tiene el centro afectivo en el caso de la mujer. 
En todas las culturas y en todos los tiempos, siempre novedosos y multifacéticos, lo femenino posee un núcleo irreductible que se trasluce en el cuerpo de la mujer, en su sensibilidad, en su modo de vivir la vida afectiva y en su dedicación a todo aquello que es propiamente humano. Los papeles socioculturales asignados a la mujer no expresan muchas veces esta identidad profunda. Al contrario, expresan el muy frecuente dominio instrumental por parte de los varones. Sin embargo, con todo y la enorme influencia que ejerce el contexto, deseamos repetir lo que desde hace algunos años hemos intentado defender: la vocación natural de la mujer parece estar orientada a la custodia de lo auténticamente bumano. Esta custodia se realiza prioritariamente en la formación del hombre y el cuidado de la rectitud en la donación interpersonal. Lamentablemente, en esta ocasión no podemos desarrollar más estas ideas pero las podemos considerar como confirmadas a través de las investigaciones de una de las más grandes filósofas del siglo veinte.

\section{LA CONTRIBUCIÓN DE EDITH STEIN}

Edith Stein, quien fuera asistente de Edmund Husserl explora, en una compilación de estudios dedicados a la mujer, el delicado tema del alma femenina. ¿Qué es lo que la caracteriza? ¿Se puede encontrar un tipo de mujer en diversas descripciones sobre el ser y hacer de las mujeres? «Se puede reducir a unidad toda la enorme variedad de mujeres que encontramos en la vida, y delimitar esta unidad frente al alma del hombre?" ${ }^{10}$. Para resolver estas cuestiones, Stein revisa tres historias diversas sobre mujeres: Ingunn, hija de Steinfinn,

${ }_{10}$ Stein, Edith., La mujer., Madrid, Palabra, 1998, p.85. 
de Sigrid Undset; Nora, de Ibsen e Ifigenia, de Goethe. Los tres son relatos de fantasía muy diferentes entre sí. Sin embargo, expresan en diversas situaciones y bajo distintos perfiles personales, un mismo rasgo esencial femenino común: «el deseo de dar amor y de recibir amor, y en ello un anhelo de elevarse desde la estrechez de su fáctica existencia actual hasta un ser y actuar superiores" ${ }^{11}$.

Poco más adelante, nuestra autora afirmará:

"¿Hemos entendido con esto el alma femenina en su núcleo? Naturalmente podrían traerse a colación todavía otros muchos tipos de mujer, pero yo creo que, en la medida en que son tipos de mujer, todos tendrán esta base común: llegar a ser aquello que ella debe ser, desplegar y madurar el mejor modo posible la humanidad que duerme en ella en la forma particular que le es requerida, hacerla madurar en aquella unión de amor que desata fructuosamente este proceso de maduración y a la vez incentivar y promover en los otros la maduración en orden a su plenitud, todo eso constituye la necesidad femenina más profunda, necesidad que puede manifestarse con muchos ropajes, también en las desviaciones y degeneraciones" ${ }^{12}$.

Este bello texto se completa con una breve consideración sobre los varones. Los varones somos más propensos a la actividad exterior, a la acción, a la realización... Éstas y otras características conducen a Edith Stein a una conclusión análoga a la nuestra:

"Yo quisiera opinar que la relación de alma y cuerpo no es completamente la misma, que por lo común la unión al cuerpo de 
forma natural es más íntima en la mujer (...). Me parece que el alma de la mujer vive y está presente con mayor fuerza en todas las partes del cuerpo, y que en consecuencia queda afectada interiormente por todo aquello que le ocurre al cuerpo, mientras que en el hombre tiene más fuertemente el carácter de instrumento que le sirve en su actuación, lo cual conlleva un cierto distanciamiento consigo mismo" ${ }^{13}$.

Esta mayor integración personal de tipo óntico tiene, sin embargo, sus riesgos. El principio vital que actualiza al cuerpo y lo hace cuerpo femenino, si no se educa en su capacidad de autodominio y autodeterminación, puede sumergirse en la dinámica de lo puramente corpóreo. De esta manera, Stein afirma categóricamente:

"Cuanto más íntima es la relación entre alma y cuerpo, tanto mayor será el peligro del hundimiento (...). Donde faltan la formación del entendimiento y la educación de la voluntad, la vida sentimental deviene un movimiento sin dirección fija. Y, porque necesita de algunas direcciones para su movimiento, cae bajo la dirección de la sensibilidad si le falta la guía de las fuerzas espirituales superiores. De este modo se produce el hundimiento de la vida espiritual en lo sensual animal, lo cual es fomentado todavía más por el fuerte vínculo con el cuerpo" ${ }^{14}$.

De esta manera podemos advertir que una emancipación femenina que suprima el desarrollo de las virtudes morales e intelectuales en la mujer -aun cuando parezca liberadora-, tenderá a esclavizarla como ningún otro ser puede ser esclavo. La corrupción de lo mejor es lo peor. La perfección propia de lo femenino si no se cultiva y desarrolla plenamente,

${ }_{14}$ Ibidem, pp.95-96. 
más tarde que temprano deviene en un sometimiento profundamente perverso. Si la cultura ambiente, por otra parte, se dinamiza por la racionalidad instrumental de tipo masculino, la combinación entre una mujer debilitada y un varón abusivo puede ser funesta.

Asimismo, como corolario, podemos advertir que una emancipación que busque liberar a la mujer imitando la peculiaridad masculina, también la colapsa debido a que su especificidad quedaría violentada y como fracturada (desintegrada). Lo propio del varón es someter su racionalidad analítica, discursiva e instrumental a la verdad que le puede descubrir la mujer. Lo propio de la mujer es educar al varón en la totalidad de los factores de lo real.

\section{SIGNIFICADO DE LA FEMINIDAD EN EL CON- TEXTO DE LA CONTROVERSIA SOBRE LO HUMANO}

La controversia de nuestro tiempo es la controversia sobre el "bumanum", lo humano ${ }^{15}$. En otras épocas, la controversia sobre el "divinum, lo divino, era muy intensa y aun cuando existían numerosas escuelas y tendencias, este tema situaba continuamente a los interlocutores en un paradigma donde era claro que todo significado de la realidad era reconducible a Dios. Al arribar la modernidad ilustrada, el tema de Dios se desplazó por alienante y sólo fue tocado por unos pocos que desde el "bumanum» buscaban una vía de acceso al «divinum»... ${ }^{16}$.

${ }^{15}$ Cfr. Szostek, Andrzej; Styczen, Tadeusz; Wojtyla, Karol., Der Streit um den Menschen. Personaler Anspruch des Sittlichen., Kevelaer, Butzon \& Bercker., 1979.

${ }^{16}$ Pienso en Malebranche, en Pascal, en Vico, en Rosmini... 
Hoy que la atención ya no está puesta en Dios, la situación no parece haber mejorado mucho, entre otras cosas, porque lo humano no parece capaz de fungir como fuente de reconducción de todos los significados. Experimentos como el kantiano muestran que cuando lo humano se reivindica al interior de la modernidad ilustrada, la manera como se recuperan los datos provenientes de la realidad tiende a ser constructivista, es decir, tiende a incubar justamente una actitud en la que el yo, más que aceptar el don de lo real, termina imponiéndose sobre él a través de una subjetividad que no reconoce otro parámetro más que el de sí misma ${ }^{17}$.

De esta manera, lo humano -aparentemente central en la modernidad ilustrada- ha sido distorsionado por una falta de conciencia sobre la primacía de lo dado. Esta falta de conciencia tiene un origen complejo que no podemos detallar aquí ${ }^{18}$. Sin embargo, como ya hemos insinuado un poco más arriba, la racionalidad instrumental fracasa entre otras cosas al momento de intentar emancipar lo humano precisamente porque privilegia la racionalidad masculina y no reconoce el aporte del ser y del hacer propiamente femenino que se caracteriza, entre otros elementos, por una búsqueda continua del carácter suprautilitario de la existencia.

No queremos indicar con esto que la racionalidad masculina sea mala per se. Lo que deseamos anotar es que cuando

17 Véase que para Kant la actividad del sujeto existe en la medida en que se refiere al yo trascendental (que es igual a una incógnita) mientras que el yo trascendental a su vez sólo se constituye por medio de esta misma actividad fundante. La circularidad de este planteamiento es patente y permeará muchos de los modelos posteriores de racionalidad autofundada. Cf. Kant, Emmanuel., Crítica de la razón pura., Madrid., Alfaguara., 1998., A 346., B 404.

${ }_{18}$ Cfr. Guerra López, Rodrigo., Volver a la persona., pp.65-75. 
ésta se construye y se educa sin el concurso de la presencia de lo femenino, la dimensión donal, gratuita, auto-dada de la existencia parece encontrar dificultad para acontecer. No tememos afirmar que pareciera que existe una relación profunda entre la captación de lo real como real y el aprecio al misterio de la persona femenina. La presencia de la mujer es esencial para configurar un modo humano de pensar, amar y actuar en la vida social.

No deja de ser curioso, a la luz de esto, que lo humano ha sido muchas veces considerado desde el enfoque de numerosas ciencias -incluida la Filosofía-, como un fenómeno en donde la diferenciación sexual no es relevante. Esto no debe ser así. La persona exige tener auténtica primacía y centralidad no sólo en el ámbito de la especulación académica sino, sobre todo, en la dinámica de la cultura y la sociedad contemporáneas. Todo esfuerzo por re-proponer a la persona como principio y fundamento requiere pasar necesariamente por re-proponer el valor de lo femenino y lo masculino, ambos rostros recíprocos y complementarios de lo humano.

El significado de la feminidad en el contexto de la controversia y crisis sobre lo humano, emerge justamente cuando nos formulamos la pregunta: "¿Quién es la mujer?", ya que esta cuestión coloca a lo femenino, de entrada, como una categoría propiamente personal y que sólo en el marco de una comprensión personalista puede ser interpretada con justicia.

Tanto en el ámbito educativo y cultural, como en el terreno de las reformas estructurales y las políticas públicas, debemos crear mecanismos que permitan que lo femenino emerja como movimiento. Esta "Vía femenina" para la reconstrucción 
de un espacio más humano en la vida privada y pública no excluye otras vías (la "vía de la solidaridad con los pobres", la "Vía educativa", la "Vía del trabajo político", etcétera) y no las excluye precisamente por su transversalidad, es decir, porque recuperar cultural y políticamente el rostro femenino de lo bumano es un quebacer que implica a todos-varones y mujeres- en todo espacio y tiempo. De este modo el preguntarnos "¿quién es la mujer?" es asumir con seriedad la propia existencia que nos ha sido muchas veces arrebatada, cuando una parte esencial de la experiencia de lo humano se margina o se excluye. Creo sinceramente que, en este sentido, la mujer es auténtica esperanza en medio de la crisis contemporánea. Su presencia, identidad y vocación son dones que todos tenemos que reaprender a apreciar, a promover y a defender.

\section{LO FEMENINO COMO DATO ANTROPOLÓGICO- NORMATIVO}

Así llegamos al punto neurálgico de nuestra exposición: ¿lo que hemos encontrado sobre la especificidad de la mujer es un dato normativo? ¿Podemos descubrir vías, desde estos datos, capaces de conducir un programa amplio de emancipación auténtica y de reconstrucción cultural y política?

Estas preguntas no son fáciles de responder. En primer lugar, pareciera que exigen una respuesta negativa ya que desde hace varios siglos, todo dato encontrado en el orden de los hechos -del ser-, parece estar cancelado como fundamento para el derecho - para el deber-ser- ${ }^{19}$. Ésta es la cuestión de la llamada "falacia naturalista". Así, una aproximación

19 Cfr. Hume, David., Tratado de la naturaleza humana., trad. cast. F. Duque, Bs. As., Orbis., 1984., T. III, 』 469-470., pp.689-690. 
al ser de la mujer no tendría ninguna utilidad para descubrir su deber ser y para, en el fondo, proponer vías metodológicas de acción emancipadora.

Sin embargo, diversos estudios recientes, desde las más diversas premisas filosóficas, parecen haber manifestado de manera elocuente que esta primera objeción es infundada ${ }^{20}$. Desde nuestro punto de vista, la denominada "falacia naturalista" cae por tierra cuando mostramos que es la propia experiencia la que apunta de hecho contenidos normativos que no exhiben simplemente cómo son las cosas sino qué se les "debe" a ellas, es decir, cómo deben ser.

En efecto, la experiencia ofrece datos que no pueden ser irrelevantes en términos de importancia y de respuesta afectiva por parte nuestra. No todos los datos experienciales son así; algunos son más bien neutros. Sin embargo, en la actividad cotidiana -en la que nos enfrentamos ante cuestiones como "¿qué debo hacer?» o "¿qué debo evitar?»-, de repente emergen respuestas "ininventables" que son como una vOz que brota de los valores con los que nos encontramos ${ }^{21}$.

El valor es un dato originario, no sólo porque es aprehendido por la razón de manera intuitiva e indubitable, sino también

${ }^{20}$ Cfr. Searle, John., Actos de habla., trad. cast. L.M. Valdés., Madrid., PlanetaAgostini., 1994., Caps. VI-VIII; Cfr. Massini, Carlos Ignacio., "Refutaciones actuales de la "falacia naturalista", en Sapientia., Bs. As., No. 2., 1984., pp.107-118; Cfr. Beuchot, Mauricio., Filosofia y derechos humanos., México., Siglo XXI., 2001., Caps. 11 y 12; Cfr. Höffe, Ottfried., Estudios sobre teoría del derecho y la justicia., trad. cast. J. M. Seña., México., Fontamara., 1997., especialmente el capítulo intitulado: Derecho natural sin falacia naturalista: un programa jusfilosófico (pp.107-134).

${ }^{21}$ Cfr. Von Hildebrand, Dietrich., op. cit. 
en el sentido de que es un dato último como lo es la esencia y el acto de ser de un ente. El valor no debe ser interpretado como una entidad desligada del ente: "Los valores son más bien el "corazón del ser", el ente mismo, en tanto que importante o valioso en sí mismo" ${ }^{22}$. Cuando sabemos que algo simplemente es, no sabemos todavía si es bueno o es malo. El conocer el valor de un ente nos muestra la perfección que posee intrínsecamente y lo apreciable que es en sí mismo. En este sentido, estamos convencidos que la comprensión filosófica de todo -especialmente de aquello que demanda ser reconocido como fin y no como medio-, no se alcanza plenamente sino hasta haber detectado su valor. El valor amplía la intensidad nocional del contenido inteligible de un ente en un grado superlativo mostrando, además de su despliegue como algo que es, su importancia o relevancia intrínseca dentro del contexto del universo. Así, los valores indican no sólo que algo es, sino que algo debe ser afirmado. Por ello, el valor incardinado en el ente funda y sostiene una invitación permanente a responder de una manera adecuada a su condición específica.

Precisamente lo femenino puede ser descubierto como un valor personal si apreciamos este dato en su integralidad. La feminidad, al no ser un accidente sino al ser un atributo que se despliega a través de toda la persona (femenina), se encuentra revestido en primer lugar de un carácter personal. Este revestimiento no se refiere a una suerte de perfección extrínseca, sino que justamente el "ser persona" en el caso de la mujer, no puede entenderse sino como "ser-persona-femenina".

${ }^{22}$ Seifert, Josef., ¿Qué es y que motiva una acción moral?, Madrid., Centro Universitario Francisco de Vitoria., 1995., p.74. 
Con más precisión podríamos decir que el subsistente singular humano (la persona, el suppositum humano) está realizado en dos modalidades diversas de acuerdo a su integración y unidad óntica: ser-varón y ser-mujer. Esto es lo que nos debe obligar a hablar siempre de persona masculina y persona femenina.

Cuando se afirma esto, puede darse la impresión -sin quererque la persona es un género (lógico) y que ser varón o ser mujer es una suerte de diferencia específica, cosa que sería del todo equivocada. La noción de persona justamente lo que busca enfatizar es que existe de manera máximamente concreta un tipo de ente que subsiste en naturaleza racional, libre y sexua$d a$. La persona es un singular en el género de la sustancia. Es un ente concreto, es un hoc aliquid que constituye una diferencia trascendental irreductible tanto a entes no personales como a otras personas. Cada persona es un ente "sui iuris et alteri incommunicabilis", es decir, no es sólo único e irrepetible como toda sustancia individual, sino que posee en grado máximo un tipo de incomunicabilidad ontológica incomparable que lo hace además ser insustituible ${ }^{23}$.

La feminidad es una perfección primariamente formal que permite un grado de articulación hilemórfica especial en la persona humana. La relación entre la naturaleza humanafemenina y la persona es la relación entre un co-principio (ens quo) y un singular subsistente (ens quod). Por ello, la normatividad que se desprende de la altísima dignidad de la persona, del subsistente humano, atraviesa la condición femenina y la convierte en una obligación objetiva primaria. 
El deber absoluto y primario que consiste en afirmar a la persona por sí misma ${ }^{24}$ no debe ser interpretado, entonces, como una norma ajena a la condición sexual sino que significa que todo ser humano está obligado, de manera categórica, a reconocer siempre a la persona femenina como fin y nunca usarla como medio. Lo femenino es el nombre de lo personal en el caso de la mujer.

\section{HIPÓTESIS PARA LA RECONSTRUCCIÓN DE LO HUMANO DESDE LA MUJER}

A la luz de estas consideraciones, afirmamos que existen cinco grandes iniciativas que es preciso construir para que la afirmación de lo humano -entendido como unidad de experiencia masculina y femenina- pueda re-proponerse de manera eficaz y no sólo como un interesante tópico teórico. En estas cinco iniciativas, el papel de la mujer es esencial debido a que es justamente el sofocamiento de lo femenino lo que, en ocasiones, ha causado una suerte de desviación en la comprensión y en la acción a favor de lo humano:

X.1. Educación de la mirada: En primer lugar, la recuperación de lo humano, reivindicando lo femenino, requiere que todos ingresemos a un proceso pedagógico de educación de la "mirada". El "mirar humano" es distinto al "ver animal». Para los animales, el ver es dejarse estimular por cualidades sensibles

${ }^{24}$ Ésta es la norma personalista de la acción, base de toda filosofía personalista auténtica: Cfr. Wojtyla, Karol., Amor y responsabilidad., Madrid., Razón y Fe., 1969. La aplicación de la norma personalista de la acción a la condición sexuada del ser humano será, años después, nuevamente aplicada en diversos textos, por ejemplo: Juan Pablo II, Hombre y mujer los creó., Madrid., Cristiandad., 2000., Cap. XV. 
que provocan reacciones instintivas y pulsionales que simplemente acaecen dentro de ellos. Los animales reciben pasivamente el entorno y, en cierto modo, también viven con cierta pasividad la propia dinámica tendencial. Por el contrario, las personas somos capaces de descubrir el significado inteligible de lo que sentimos y vivimos en el plano instintivo, pulsional y propiamente afectivo. Los significados no son cualidades sensibles sino meta-sensibles que nos permiten descubrir que la persona posee realmente una capacidad propiamente intelectual, gracias a la cual puede comprender (nunca exhaustivamente) lo que sucede en el mundo y en sí mismo. Además, la persona es capaz de trascender estos dinamismos sin negarlos, gracias al autodominio que posibilita nuestra voluntad que, al seguir lo que la razón le descubre como verdaderamente bueno, puede alcanzar un grado de perfección operativa y de auténtica soberanía como ningún otro ser en el universo. Así es como la libertad se vuelve condición de posibilidad de la educación de la persona en general y de la "mirada" en particular.

La cultura ambiente en la que nos encontramos sumergidos se encuentra en un momento delicado de cambio epocal que influye de manera decisiva en el proceso de educación de la mirada. El mirar instrumental moderno-ilustrado no termina de agotarse y el mirar evasivo de la posmodernidad no acaba de llegar. Si hablamos de "mirar" instrumental y evasivo es precisamente porque todos, en mayor o menor medida, hemos sido educados -tal vez sin mucha conciencia- por este entorno cultural en crisis. En este punto vale la pena advertir que la mirada no se educa con exposiciones teóricas sobre la persona, sino creando un ethos, a través de la acción, que permita descubrir existencialmente la belleza 
que existe al apreciar los valores y en especial el valor que porta lo humano.

De este modo, reivindicar lo humano y la dimensión femenina de lo humano pasa por la mirada, es decir, por el esfuerzo racional y volitivo para que el modo como yo afronto el desafío que me muestra el rostro del otro, no se convierta en un afán de dominio instrumental. Las mujeres, muchas veces sin utilizar por supuesto estos términos más bien académicos, captan de manera intuitiva la mirada instrumental de nosotros, los varones no educados, que pareciera reducirlas a un mero objeto de uso. Si bien es cierto que todos debemos educar nuestra mirada a través de la construcción de un nuevo ethos social más contemplativo y menos utilitario, los varones somos sin duda un caso que requiere de una urgente atención pedagógica particular ${ }^{25}$.

X.2. Generar movimiento cultural: Un ethos renovado, es decir, un conjunto de valores realmente vividos en la vida cotidiana (Lebenswelt), no es acción de una persona en solitario. La cultura es una construcción intersubjetiva en la que la experiencia de lo humano de cada persona se participa. Es precisamente en el ser y actuar junto-con-otros donde la experiencia de lo humano se afirma o se niega a través de la acción ${ }^{26}$. Por

${ }^{25}$ Es útil para ampliar esta reflexión, considerar el fenómeno de la ceguera axiológica. Cfr. Crespo, Mariano., La ceguera al valor moral. Consideraciones en torno a la "antropología integral" de Dietrich von Hildebrand (promanuscripto); Cfr. Von Hildebrand, Dietrich., Sittlichkeit und Ethische Werterkenntnis. Eine Untersuchung über Ethische Strukturprobleme., Vallendar-Schönstatt, Patris Verlag., 1982.

${ }^{26}$ Cfr. Wojtyla, Karol., "Il problema del costituirsi Della cultura attraverso la "praxis" umana", Rivista di Filosofia Neo-Scolastica, anno LXIX., lugliosettembre., 1977, fascicolo III., pp.513-524. 
ello, es preciso buscar de manera deliberada formas estables de vida solidaria. La humanización del mundo a través de la recuperación de lo femenino no puede darse si no se muestra, de manera sociológicamente identificable, que es posible vivir de un nuevo modo la interacción entre varones y mujeres. No bastan la incidencia en los medios de comunicación o los proyectos de reforma legislativa. En la base de ellos es necesario que exista una experiencia "comunional" que posibilite mirar de un modo diverso lo real y, desde esa reciprocidad en las miradas, aprender a ofrecer creativamente propuestas de transformación estructural.

Toda reforma estructural que prescinde del trabajo lento y tal vez poco glamoroso en el orden cultural -es decir, en el orden de la creación de un movimiento que viva de un ethos renovado-, tiende a decaer y agotarse aun cuando esté bien diseñada técnicamente.

X.3. No abandonar la acción organizada para la transformación estructural: El compromiso con la mujer tiene que volverse agenda política. Justamente una asunción seria de la cuestión femenina, que evite la frivolidad y que busque incidencia, debe atreverse a mostrar, en el espacio público, que es posible crear leyes e instituciones en los que el aporte femenino sea revalorado. Este tipo de acción requiere no sólo de una experiencia "comunional", sino de la visión estratégica propia de la actividad política. Para nadie es desconocido el terrible desprestigio que la política sufre en la actualidad. Sin embargo, esta lamentable situación no debe ser motivo para abstraernos de este tipo de desafíos. El descuido de la acción política, el dejarle la acción política a otros actores, ha sido una de las causas principales por las que una gran cantidad 
de valores, incluido el propio de la mujer, han quedado como desplazados socialmente a través de la Historia.

Considero que si bien el papel del académico -y más aún el del filósofo- es ciertamente diverso al papel del político, no es posible continuar creyendo que una verdadera exploración de lo real, en cuanto real, puede hacerse al margen de un involucramiento profundo en las luchas a favor de la justicia que en el orden político es preciso librar. Por otra parte, esto no es una novedad: la función social de los saberes liberales, es decir, de los saberes altamente especulativos y teoréticos, es una dimensión constitutiva de los mismos ${ }^{27}$.

X.4. Re-proponer las razones del Derecho: Una consecuencia de lo anterior es la necesidad de asegurar los mínimos de justicia que se requieren para que la vida humana en sociedad pueda darse. En este sentido, los derechos de la mujer no son entonces un capítulo más entre un gran conjunto de temas y problemas en el ámbito de lo jurídico. Al contrario, la emergencia cultural de la especificidad femenina requiere siempre de un adecuado reconocimiento normativo-positivo en el que los "derechos de la mujer" no se tornen un subconjunto dentro del más amplio capítulo de los derechos humanos. Una comprensión personalista de lo femenino exige que los derechos de la mujer incluyan todos los derechos que brotan de la dignidad personal y los derechos que brotan de la especificidad femenina. Así, es posible reclamar como derecho propio de la mujer, no sólo cosas como el derecho a ser madre, sino el derecho al trabajo, a la educación, a la libertad de expresión, etcétera...

${ }^{27}$ Cfr. Millán-Puelles, Antonio., La función social de los saberes liberales., Madrid., Rialp., 1961. 
A este respecto vale la pena mencionar que los derechos de la mujer son no sólo derechos civiles y políticos, sino también todos los derechos económicos, sociales y culturales que habrán de ser promovidos y defendidos desde la experiencia femenina.

Más aún: si entendemos que custodiar lo humano es un bien no sólo individual sino de todos como sujeto social, podemos también entrever que los derechos de la mujer son parte del bien común y por ello, son un derecho tanto de las personas como de los pueblos. La solidaridad entre los pueblos, vivida bajo un esquema de derechos y obligaciones, tiene precisamente como base la existencia de un bien máximamente común que sólo en común -es decir, con el concurso de todos- puede ser efectivamente protegido.

Los derechos de la mujer como derechos civiles, políticos, económicos, sociales, culturales y solidarios exigen que no dejemos como algo absurdo el fascinante tema del fundamento último de los mismos. Norberto Bobbio, filósofo italiano recientemente fallecido, sostenía continuamente que es una "ilusión" indagar el fundamento de los derechos en general. Para este pensador basta el ponerse de acuerdo en el orden práctico para que los derechos humanos posean solidez y obligatoriedad ${ }^{28}$. Nosotros no podemos negar que el consenso es una herramienta importante para fundar politicamente los derechos humanos en el marco de una sociedad plural y democrática. Sin embargo, el fundamento político no puede ser confundido con el siempre necesario fundamento

${ }^{28}$ Por ejemplo, véase Bobbio, Norberto., "Sobre el fundamento de los derechos del hombre" $\mathrm{y}$ "Presente y futuro de los derechos del hombre", ambos publicados en El problema de la guerra y las vías para la paz., Barcelona., Altaza., 1999. 
filosófico. Si se prescinde de este último, preguntas cómo "¿por qué debo respetarte?» no pueden ser respondidas cabalmente y más pronto que tarde esta debilidad abre la puerta para que el poder se imponga sobre la dignidad de las personas.

X.5. Volver a la persona: Si tuviésemos que sintetizar los cuatro puntos anteriores en una sola expresión, tendríamos que afirmar que el programa a realizar es precisamente "volver a la persona". La verdad sobre el hombre consiste en existir como persona, es decir, en ser un sujeto singular capaz de comprender y de amar, capaz de reconocer su límite y al mismo tiempo reconocer su insaciable ansia de encontrar un significado personal y absoluto para la vida. La experiencia de la alteridad, basada en la diferenciación sexual, es sin lugar a dudas una proto-experiencia "comunional" que nos permite presentir la existencia de nuestra vocación a una comunión mayor que la que nuestras propias fuerzas pueden proporcionarnos.

"Volver a la persona", es entonces, volver a reconocer en su identidad y en su diferencia al varón y a la mujer. Pero más aún: volver a la persona es vivir esta diferencia siempre bajo el amparo de una "mirada" que antes que la nuestra nos ha querido en nuestro valor verdadero. Así las cosas, el horizonte en el que la dignidad femenina tiene que ser revindicada es el que se abre cuando tú y yo acogemos en comunión la posibilidad de un Misterio que salve.

Que esta última frase no se vuelva una expresión meramente pía sino que ofrezca para todos un programa de vida con alcance personal, social y político es precisamente una razón para mantener la esperanza y para continuar luchando a favor de la mujer y su dignidad. 


\section{REFERENCIAS BIBLIOGRÁFICAS}

A.A. V.V., Temas actuales de Bioética., México., Editorial Porrúa., 1999.

AGUSTÍN DE HIPONA., "De Trinitate" en Obras de San Agustín., Vol. V., BAC., Madrid., 1982.

BADINTER, Elisabeth., L'un est 1' autre. Des relations entre hommes et femmes., París., Odile Jacob., 1986.

BEUCHOT, Mauricio., Filosofia y derechos humanos., México., Siglo XXI., 2001.

BOBBIO, Norberto., "Sobre el fundamento de los derechos del hombre" y "Presente y futuro de los derechos del hombre", ambos publicados en El problema de la guerra y las vías para la paz., Barcelona., Altaya., 1999.

CARDONA, Carlos., Metafísica del bien y del mal., Pamplona., Eunsa., 1987.

CRESPO, Mariano., La ceguera al valor moral. Consideraciones en torno a la «antropología integral» de Dietrich von Hildebrand (promanuscripto).

GOLDBERG, Steven., La inevitabilidad del patriarcado., Madrid., Alianza., 1976.

GÓMEZ PÉREZ, Rafael., Introducción a la metafísica., Madrid., Rialp., 1978., p.57.

GUERRA LÓPEZ, Rodrigo., "Pensar la diferencia. Reflexiones sobre la condición femenina y el fundamento antropológico de la diferenciación sexual", en Medicina y Ética. Revista Internacional de Bióetica, Deontología y Ética Médica., Facoltá di Medicina e Chirurgia dell'Universitá del Sacro CuoreUniversidad Anáhuac., Vol. VII., No. 4., octubre-diciembre., 1996. 
GUERRA LÓPEZ, Rodrigo., Afirmar a la persona por sí misma. La dignidad como fundamento de los derechos de la persona., México., Comisión Nacional de los Derechos Humanos., 2003.

GUERRA LÓPEZ, Rodrigo., Volver a la persona. El método filosófico de Karol Wojtyla., Madrid., Caparrós., 2002. HÖFFE, Ottfried., Estudios sobre teoría del derecho y la justicia., trad. cast. J. M. Seña., México., Fontamara., 1997. HUME, David., Tratado de la naturaleza humana., trad. cast. F. Duque., Bs. As., Orbis., 1984.

JUAN PABLO II., Hombre y mujer los creó., Madrid., Cristiandad., 2000.

KANT, Immanuel., Crítica de la razón pura., Madrid., Alfaguara., 1998.

MASSINI, Carlos Ignacio., "Refutaciones actuales de la "falacia naturalista”., Sapientia., Bs. As.., No. 2., 1984.

MILLÁN-PUELLES, Antonio., La función social de los saberes liberales., Madrid., Rialp., 1961.

SCOLA, Angelo., Identidad y diferencia. La relación hombre-mujer., Madrid., Encuentro., 1989.

SEARLE, John., Actos de habla., trad. cast. L. M. Valdés., Madrid., Planeta-Agostini., 1994.

SEIFERT, Josef., ¿Qué es y que motiva una acción moral?, Madrid., Centro Universitario Francisco de Vitoria., 1995.

SEIFERT, Josef., "Defender a la mujer del feminismo", en Atlántida., Vol. VI., No. 13., enero-marzo., 1993., pp.17-27. STEIN, Edith., La mujer., Madrid., Palabra., 1998.

SZOSTEK, Andrzej; Styczen, Tadeusz; Wojtyla, Karol., Der Streit um den Menschen. Personaler Anspruch des Sittlichen., Kevelaer., Butzon \& Bercker., 1979.

TOMÁS DE AQUINO, De Veritate., Ed. Marietti., Turín-Roma., 1964. 
VON HILDEBRAND, Dietrich., Ética., Madrid., Encuentro., 1983.

VON HILDEBRAND, Dietrich., Sittlichkeit und Ethische Werterkenntnis. Eine Untersuchung über Ethische Strukturprobleme., Vallendar-Schönstatt., Patris Verlag., 1982.

WOJTYLA, Karol., "Il problema del costituirsi Della cultura attraverso la "praxis" umana", Rivista di Filosofia NeoScolastica., anno LXIX., luglio-settembre., 1977., fascicolo III., pp.513-524.

WOJTYLA, Karol., Amor y responsabilidad., Madrid., Razón y Fe., 1969.

WOJTYLA, Karol., Metafisica della persona., Milano., Bompiani., 2003. 